\title{
REVIEW
}

\section{Cell adhesion molecules in cardiovascular disease: a clinical perspective}

\author{
G S Hillis, A D Flapan
}

The adhesion of cells to each other and to the proteins of the extracellular matrix provides a stable environment for cell growth, differentiation, and migration. This is a prerequisite for the normal function of all components of the cardiovascular system. Adhesive interactions, however, are also involved in the pathogenesis of cardiovascular disease, regulating thrombus formation, facilitating leucocyte infiltration, mediating the migration and proliferation of smooth muscle cells, and enabling the deposition of fibrotic tissue. There is, therefore, increasing interest in the receptors that determine these processes-cell adhesion molecules.

Three main groups of adhesion molecules have been implicated in cardiovascular pathology: integrins, selectins, and members of the immunoglobulin superfamily. The structure and function of these molecules is outlined briefly, followed by an assessment of their importance in cardiac disease.

\section{Structure and function of cell adhesion molecules \\ INTEGRINS}

Integrins are glycoproteins composed of two subunits, the $\alpha$ and $\beta$ chains (fig 1 ). As their name suggests they mediate the adhesion of cells to each other and to surrounding substrates, "integrating" the cell with its environment. ${ }^{1}$ In addition, they straddle the cell membrane and play an important role in initiating intracellular events in response to extracellular stimuli. ${ }^{2}$ The most widely distributed integrins belong to the $\beta_{1}$ subfamily, which mainly influence the adhesion of cells to extracellular matrix proteins such as fibronectin, collagens, and laminin (table 1). The $\beta_{2}$ integrins are expressed solely by white cells and principally interact with members of the immunoglobulin superfamily promoting leucocyte adhesion and infiltration. The $\beta_{3}$ family has two principal members (table 1) with differing, but important, functions. Activation of the $\alpha_{\mathrm{II}} \beta_{3}$ or glycoprotein IIb/IIIa receptor is the final step in platelet aggregation and determines the adhesion of platelets to other matrix and plasma proteins. This allows them to bind to vascular endothelium and exposed subendothelial proteins. The second $\beta_{3}$ integrin, $\alpha_{v} \beta_{3}$, has a wide cellular and ligand distribution, and is involved in several important biological functions such as angiogenesis. Although an increasing number of new $\alpha$ and $\beta$ subunits have been described recently their biological roles have yet to be fully determined. In general, however, they seem similar to those already described.

\section{SELECTINS}

Unlike other adhesion receptors, selectins bind to carbohydrates and glycopeptides rather than protein ligands (table 2 ). There are three principal members of this family-L, P, and E selectin, named after the cell types in which they were first identified (lymphocytes, platelets, and endothelial cells). ${ }^{3}$ The main role of selectins is the tethering of leucocytes to the endothelium. They induce relatively weak and transient adhesion allowing the cells to roll along the vascular wall after which they will disengage or, following the triggering of other adhesion receptors such as integrins, become more securely bound.

IMMUNOGLOBULIN SUPERFAMILY

Immunoglobulin molecules such as the intercellular adhesion molecules (ICAM-1, 2, and 3 ), vascular cell adhesion molecule 1 (VCAM1), and platelet endothelial cell adhesion molecule 1 (PECAM-1) are principally involved in the adhesion of leucocytes (table 2). ${ }^{4}$ ICAM-1 and 2 are expressed on endothelial cells, lymphocytes, and some other leucocytes. They determine a variety of lymphocyte functions but, perhaps more importantly in the context of cardiovascular disease, they also play a pivotal role in the "trafficking" of leucocytes through tissues, interacting with $\beta_{2}$ integrins on white cells. $^{5}$

VCAM-1 is expressed on activated endothelial cells and participates in leucocyte extravasation (in particular, the efflux of monocytes, basophils, eosinophils, and lymphocytes). Following the rolling stage (described above) various factors may activate white cell membrane integrins, including $\beta_{2}$ receptors and the $\alpha_{4} \beta_{1}$ molecule, which binds specifically to VCAM-1 and helps to secure leucocytes tightly to the vascular wall.

PECAM-1 contributes to the interaction between leucocyte integrins and other members of the immunoglobulin superfamily by augmenting the activity of the former molecules. Its other main functions are to regulate
Dr Hillis.

Accepted for publication 5 January 1998 

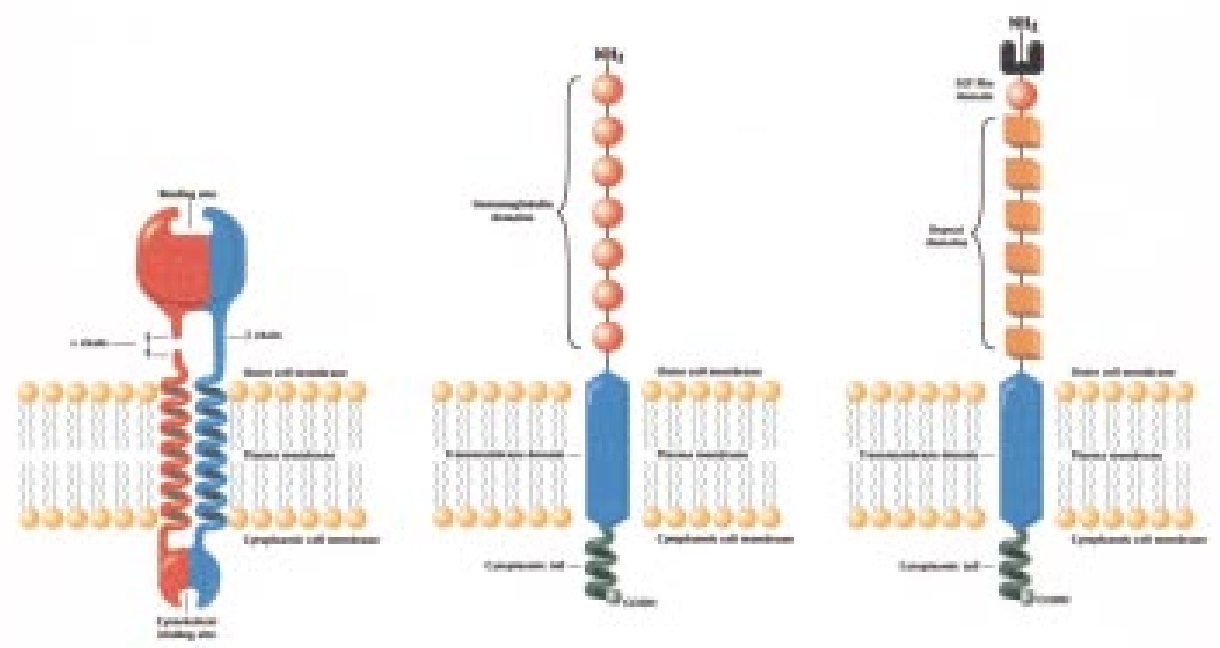

Figure 1 Schematic representations of integrin (left), immunoglobulin superfamily (centre), and selectin (right) adhesion molecule structures.

the migration of leucocytes between endothelial cells, and to promote the release of protease enzymes from neutrophils, further assisting their passage into the extracellular space.

\section{Cell adhesion molecules and cardiovascular pathology}

Although adhesion molecules are vital for the normal development and function of the heart and blood vessels ${ }^{6}$ they have also been implicated in the pathogenesis of cardiovascular disease.

CORONARY ARTERY DISEASE

Cell adhesion molecules play an important role in the development of several chronic fibroproliferative diseases such as glomerulosclerosis,

Table 1 Integrin-ligand interactions

\begin{tabular}{|c|c|c|}
\hline $\begin{array}{l}\text { Adhesion } \\
\text { molecule }\end{array}$ & Other names & $\operatorname{Ligand}(s)$ \\
\hline \multicolumn{3}{|c|}{$\beta_{1}$ integrins } \\
\hline$\alpha_{1} \beta_{1}$ & VLA-1, CD49a/CD29 & Laminin (collagen I and IV) \\
\hline$\alpha_{2} \beta_{1}$ & VLA-2, CD49b/CD29 & Collagen I and IV (laminin) \\
\hline$\alpha_{3} \beta_{1}$ & VLA-3, CD49c/CD29 & Fibronectin, laminin, collagen I, epiligrin, invasin \\
\hline$\alpha_{4} \beta_{1}$ & VLA-4, CD 49d/CD29 & Fibronectin, VCAM-1, invasin \\
\hline$\alpha_{5} \beta_{1}$ & VLA-5, CD49e/CD29 & Fibronectin, invasin \\
\hline$\alpha_{6} \beta_{1}$ & VLA-6, CD49f/CD29 & Laminin, invasin \\
\hline$\alpha_{7} \beta_{1}$ & - & Laminin \\
\hline$\alpha_{8} \beta_{1}$ & - & Vitronectin, fibronectin, tenascin \\
\hline$\alpha_{9} \beta_{1}$ & - & Collagen, laminin, tenascin \\
\hline$\alpha_{\mathrm{v}} \beta_{1}$ & CD51/CD29 & Fibronectin, vitronectin \\
\hline \multicolumn{3}{|c|}{$\beta_{2}$ integrins } \\
\hline$\alpha_{\mathrm{L}} \beta_{2}$ & LFA-1, CD11a/CD18 & ICAM-1, ICAM-2 \\
\hline$\alpha_{M} \beta_{2}$ & Mac-1, CD11b/CD18 & $\begin{array}{l}\text { Complement component C3bi, fibrinogen, ICAM-1, } \\
\text { factor X }\end{array}$ \\
\hline$\alpha_{\mathrm{x}} \beta_{2}$ & p150,95, CD11c/CD18 & Complement component C3bi, fibrinogen \\
\hline$\alpha_{\mathrm{D}} \beta_{2}$ & - & $?$ \\
\hline \multicolumn{3}{|c|}{$\beta_{3}$ integrins } \\
\hline$\alpha_{\mathrm{IIb}} \beta_{3}$ & gpIIbIIIa, CD41/CD61 & Fibrinogen, von Willebrand factor, fibronectin \\
\hline$\alpha_{\mathrm{v}} \beta_{3}$ & CD51/CD61 & $\begin{array}{l}\text { Vitronectin, thrombospondin, fibrinogen, fibronectin, } \\
\text { von Willebrand factor }\end{array}$ \\
\hline$\alpha_{\mathrm{R}} \beta_{3}$ & - & $\begin{array}{l}\text { Vitronectin, fibrinogen, fibronectin, von Willebrand } \\
\text { factor }\end{array}$ \\
\hline \multicolumn{3}{|c|}{ Other integrins } \\
\hline$\alpha_{6} \beta_{4}$ & - & Laminin/basement membrane \\
\hline$\alpha_{\mathrm{v}} \beta_{5}$ & $\alpha_{\mathrm{v}} \beta_{\mathrm{x}}, \alpha_{\mathrm{v}} \beta_{\mathrm{s}}$ & Vitronectin \\
\hline$\alpha_{\mathrm{v}} \beta_{6}$ & - & Fibronectin \\
\hline$\alpha_{4} \beta_{7}$ & $\alpha_{\mathrm{v}} \beta_{\mathrm{P}}, \mathrm{LPAM}-1$ & Peyers patch, addressin, fibronectin, VCAM-1 \\
\hline$\alpha_{\mathrm{E}} \beta_{7}$ & - & E cadherin \\
\hline$\alpha_{\mathrm{v}} \beta_{8}$ & - & ? \\
\hline
\end{tabular}

cirrhosis, pulmonary fibrosis, and atherosclerosis. ${ }^{7}$ The infiltration of monocytes and $\mathrm{T}$ lymphocytes, which initiates the atherosclerotic process, is mediated by adhesion receptors. Once they have entered the vascular wall, leucocytes release a variety of cytokines and other bioactive molecules. This results in the proliferation and migration of smooth muscle cells and subsequently promotes the deposition of excess connective tissue. ${ }^{8}$ These actions are primarily regulated by $\beta_{1}$ integrins, although VCAM-1 is also expressed strongly on the surface of activated smooth muscle cells and may help to retain leucocytes within atherosclerotic vessels. ${ }^{9}$

The $\alpha_{v} \beta_{3}$ integrin has been demonstrated in atherosclerotic plaques ${ }^{10}$ and may be a therapeutic target that, if blocked, could prevent the formation of new vessels-reducing plaque growth and the migration of smooth muscle cells into the vessel intima. Conversely, in some circumstances angiogenesis may be beneficial-allow the revascularisation of ischaemic tissue. The role of integrins such as $\alpha_{v} \beta_{3}$ and $\alpha_{v} \beta_{5}$ in this situation remains to be fully determined.

The involvement of cell adhesion molecules in transplant vasculopathy and restenosis following angioplasty is analogous to their role in atherosclerosis. Certainly there are reports of increased leucocyte integrin expression following percutaneous transluminal coronary angioplasty, and correlations between this and subsequent adverse clinical events. ${ }^{11}$ In a murine angioplasty model ICAM-1 is strongly expressed by medial smooth muscle cells in the 48 hours following balloon injury, and a few days later in the expanding vessel intima and regenerating endothelium. ${ }^{12}$ A monoclonal antibody towards this receptor reduces the degree of neointimal hyperplasia without reducing monocyte infiltration suggesting that the benefits result from its effects on intrinsic cells rather than leucocyte extravasation. Despite this, increases in white cell integrins have been implicated in the pathogenesis of unstable 
Table 2 Selectin and immunoglobulin superfamily-ligand interactions

\begin{tabular}{|c|c|c|}
\hline Adhesion molecule & Other names & $\operatorname{Ligand}(s)$ \\
\hline \multicolumn{3}{|l|}{ Selectins } \\
\hline E selectin & CD62E, ELAM-1, LECCAM-2 & sLe $^{\mathrm{x}}$, sLe $^{\mathrm{a}}$, GlyCAM-1 \\
\hline L selectin & CD62L, Mel-14, LECCAM-1 & $\begin{array}{l}\text { sLe }{ }^{\mathrm{x}} \text {, sLe }{ }^{\mathrm{a}} \text {, GlyCAM-1, CD } 34, \\
\text { LAM-1MAdCAM-1, fucoidin }\end{array}$ \\
\hline$P$ selectin & $\begin{array}{l}\text { CD62P, GMP140, LECCAM-3, } \\
\text { PADGEM }\end{array}$ & $\mathrm{Le}^{\mathrm{x}}, \mathrm{sLe}^{\mathrm{x}}, \mathrm{sLe}^{\mathrm{a}}$, fucoidin, PSGL- 1 \\
\hline \multicolumn{3}{|c|}{ Immunoglobulin superfamily } \\
\hline ICAM-1 & CD54 & $\alpha_{\mathrm{L}} \beta_{2}, \alpha_{M} \beta_{2}$ \\
\hline ICAM-2 & - & $\alpha_{\mathrm{L}} \beta_{2}$ \\
\hline ICAM-3 & - & $\alpha_{\mathrm{L}} \beta_{2}$ \\
\hline PECAM-1 & CD31, EndoCAM & CD31 \\
\hline VCAM-1 & INCAM 110 & $\alpha_{4} \beta_{1}, \alpha_{4} \beta_{7}$ \\
\hline LFA-2 & CD2 & LFA-3 \\
\hline LFA-3 & CD58 & LFA-2 \\
\hline
\end{tabular}

angina, although their relation with eventual outcome remains undetermined. ${ }^{13}$

Several cell adhesion molecules are found in soluble form within the serum, shed principally from endothelial cells and, in the case of $P$ selectin, platelets. Increased amounts of soluble ICAM-1 and E selectin have been found in patients with atherosclerosis, ${ }^{14}$ while soluble VCAM-1 and $P$ selectin concentrations are unchanged in stable atherosclerotic disease. In unstable coronary syndromes, however, P selectin does increase, presumably reflecting the activation of platelets and endothelial cells. ${ }^{15}$ Endothelial activation also results in increased amounts of soluble E selectin. These predict restenosis following peripheral angioplasty, ${ }^{16}$ suggesting that blockade of adhesion receptors may be a useful therapeutic approach to this problem.

THROMBOSIS

Thrombus formation is an important feature of chronic vascular disease and is, of course, central in acute coronary syndromes. Activation of the $\alpha_{\mathrm{IIb}} \beta_{3}$ receptor can result in platelet adhesion even if the arachidonic acid pathway is blocked. Several large clinical trials have demonstrated the value of anti- $\alpha_{\mathrm{II}} \beta_{3}$ treatment in settings such as high risk coronary angioplasty and unstable angina, ${ }^{17}$ and agents such as abciximab are now standard treatment. In addition $\alpha_{v} \beta_{3}$ has a variety of important biological functions, and some of the beneficial long term effects of non-selective anti- $\beta_{3}$ antibodies may relate to effects on this receptor.

OTHER CARDIOVASCULAR DISEASES

Blockade of adhesion molecules has been used to prevent and treat the rejection of a variety of allografts. In primates the rejection of transplanted hearts can be reduced by the administration of anti-ICAM-1 or anti-VCAM-1 antibodies. ${ }^{18}$ Although similar strategies have been used with varying degrees of success to prevent the rejection of human renal grafts there are, as yet, no large scale clinical trials.

Recently there have been reports of adhesion molecule expression in myocardial diseases such as viral myocarditis and cardiomyopathy, where their presence correlates with inflammatory cell infiltration. It remains to be seen, however, whether these offer any hope of novel treatments or merely represent interesting insights into the pathogenesis of such conditions.

Certainly, studies using antibodies capable of blocking leucocyte integrins, ICAM-1 or selectins to prevent reperfusion injury in animal models of myocardial infarction ${ }^{18}{ }^{19}$ do suggest a therapeutic potential, and there are sound theoretical reasons to support such an approach. It should be acknowledged, however, that experimental results are variable and that some degree of inflammation following tissue damage is a physiological response necessary for repair and scar formation.

\section{Summary}

In summary, there is increasing evidence that cell adhesion molecules play an important role in cardiovascular pathology. They are involved in the main processes that underlie cardiac disease including thrombosis, leucocyte infiltration, smooth muscle proliferation, and cell migration. Anti-integrin treatment is already widely used to treat thrombotic complications, and it seems likely that manipulation of other cell adhesion molecules will be used clinically in the near future.

1 Hynes RO. Integrins: a family of cell surface receptors. Cell 1987;48:549-54

2 Hynes RO. Integrins: versatility, modulation, and signalling in cell adhesion. Cell 1992;69:11-25.

3 Bevilacqua MP, Nelson RM. Selectins. f Clin Invest 1993;91:379-87.

4 Springer TA. Adhesion receptors of the immune system. Nature 1990;346:425-34.

5 Adams DH, Shaw S. Leucocyte-endothelial interactions and regulation of leucocyte migration. Lancet 1994;343: 831-6.

6 Ruoslahti E, Engvall E. Integrins and vascular extracellular matrix assembly. $\mathcal{F}$ Clin Invest 1997;99:1149-52.

7 Hillis GS, MacLeod AM. Integrins in disease. Clin Sci 1996;91:639-50.

8 Ross R. Cell biology of atherosclerosis. Annu Rev Physiol 1995;57:791-804.

9 Libby P, Li H. Vascular cell adhesion molecule-1 and smooth muscle cell activation during atherogenesis. $\mathcal{f}$ Clin Invest 1993;92:538-9.

10 Hoshiga M, Alpers CE, Smith LL, et al. $\alpha_{\mathrm{v}} \beta_{3}$ integrin expression in normal and atherosclerotic artery. Circ Res 1995;77:1129-35.

11 Mickelson JK, Lakkis NM, Villarreal-Levy G, et al. Leukocyte activation with platelet adhesion after coronary angioplasty: a mechanism for recurrent disease? $\mathcal{F} \mathrm{Am}$ Coll Cardiol 1996;28:345-53.

12 Yasukawa $\mathrm{H}$, Imaizumi $\mathrm{T}$, Matsuoka $\mathrm{H}$, et al. Inhibition of intimal hyperplasia after balloon injury by antibodies to intercellular adhesion molecule-1 and lymphocyte intercellular adhesion molecule-1 and lymphocyte 22 .

13 Mazzone A, De Servi S, Ricevuti G, et al. Increased expression of neutrophil and monocyte adhesion molecules in unstable coronary artery disease. Circulation 1993;88:35863.

14 Blann AD, McCollum CN. Circulating endothelial cell/ eukocyte adhesion molecules in atherosclerosis. Thromb Haemost 1994;72:151-4.

15 Ikeda $\mathrm{H}$, Takajo $\mathrm{Y}$, Ichiki $\mathrm{K}$, et al. Increased soluble form of P-selectin in patients with unstable angina. Circulation 1995;92:1693-6.

16 Belch JJF, Shaw JW, Kirk G, et al. The white blood cell adhesion molecule E-selectin predicts restenosis in patients with intermittent claudicatio with intermittent claudication undergoing percutaneo

17 Lefkovits J, Plow EF, Topol EJ. Platelet glycoprotein IIb/IIIa receptors in cardiovascular medicine. $N$ Engl $f \mathrm{Med}$ 1995;332:1553-9.

18 Jang Y, Lincoff AM, Plow EF, et al. Cell adhesion molecules in coronary artery disease. 7 Am Coll Cardiol 1994;24: in coronary

19 Ma XL, Lefer DJ, Lefer AM, et al. Coronary endothelial and cardiac protective effects of a monoclonal antibody to intercellular adhesion molecule- 1 in myocardial ischemia and reperfusion. Circulation 1992;86:937-46. 